\title{
Updating predictors of endoscopic recurrence after ileocolic resection for Crohn disease
}

\author{
Sara Monteiro 1,2,3, Tiago Cúrdia Gonçalves ${ }^{1,2,3}$, Pedro Boal Carvalho 1,2,3, Maria João Moreira 1,2,3, José Cotter,2,3 \\ 'Department of Gastroenterology, Hospital da Senhora da Oliveira-Guimarães, Portugal \\ ${ }^{2}$ University of Minho School of Medicine, Braga, Guimarães, Portugal \\ ${ }^{3}$ Associate Laboratory ICVS, 3B's, Braga, Guimarães, Portugal
}

Cite this article as: Monteiro S, Gonçalves TC, Carvalho PB, Moreira MJ, Cotter J. Updating predictors of endoscopic recurrence after ileocolic resection for Crohn disease. Turk J Gastroenterol 2017; 28: 260-5.

\begin{abstract}
Background/Aims: Identifying predictors of endoscopic recurrence (ER) has become very important to guide the decision of postoperative strategy. This study aimed to determine the rate of endoscopic recurrence until 12 months after ileocolic resection for Crohn disease (CD) in a cohort and identify its possible predictors.

Materials and Methods: We conducted a retrospective single-center study that included patients with CD who underwent ileocolic resection between 2003 and 2014. ER was defined according to the Rutgeerts'score, defined as i2, i3, or i4 at ileocolonoscopy that was performed 6-12 months after surgery. The patients were classified into two groups according to the Rutgeerts' score: non-ER (Rutgeerts i0/i1) and ER (Rutgeerts $\geq i 2$ ). Multivariate logistic regression analysis was performed, including significant variables on univariable analysis, to identify ER predictors.

Results: Forty-two patients were included. The mean period of the first postoperative colonoscopy was 9 months, and ER was observed in 25 patients (59.5\%). The perianal disease and shorter duration of CD were the only ER predictors ( $p=0.024 ; O R, 8.36 ; 95 \% \mathrm{Cl}, 1.329-52.642$ and $p=0.039 ; \mathrm{OR}, 0.965 ; 95 \% \mathrm{Cl}, 0.933-0.998$, respectively).

Conclusion: Endoscopic recurrence affects almost two-thirds of patients with CD after ileocolic resection, with perianal involvement and a shorter duration of disease being significant risk factors. These factors may indicate a more aggressive disease associated with rapid progression and support the need of intensive early treatment to improve patients' outcomes.
\end{abstract}

Keywords: Crohn disease, endoscopy, surgery

\section{INTRODUCTION}

Crohn disease (CD) is characterized for periods of exacerbation that alternate with periods of remission (1). Even with the great advances on CD pathogenesis and available therapeutic options, most of the patients require an intestinal surgery during their lifetime $(1,2)$.

Endoscopic recurrence (ER) is defined as the reappearance of lesions after complete surgical resection. New lesions can recur in the anastomotic region within weeks to months of surgery, and after ileal resection, nearly $80 \%$ of the patients have new lesions in the neoterminal ileum within 1 year after resection $(3,4)$.
Endoscopic recurrence is determined by the presence of inflammation and ulceration and is categorized according to the Rutgeerts' score (3). There is a gap between clinical recurrence and $E R$, and the severity of endoscopic lesions post-surgery predict clinical relapse (3). Once clinical relapse interferes with the patient's quality of life, it is essential to stratify the risk for post-surgery relapse (5). Therefore, an ileocolonoscopy evaluation within the first year after resection may be useful for stratifying patients at a high risk for clinical recurrence (3).

This study aimed to determine the rate of ER and to determine ER predictors in patients with $C D$ at 6-12 months after surgery.

This study was presented at the $11^{\text {th }}$ Congress of ECCO, 16-19 March 2016, Amsterdam, Netherlands.

Address for Correspondence: Sara Monteiro E-mail: sara.s.o.monteiro@gmail.com

Received: December 14, 2016 Accepted: March 7, $2017 \quad$ Available Online Date: June 7, 2017

(c) Copyright 2017 by The Turkish Society of Gastroenterology • Available online at www.turkjgastroenterol.org • DOI: 10.5152/tjg.2017.16721 


\section{MATERIALS AND METHODS}

We reviewed and analyzed the medical records of a cohort at a single center who underwent ileocolic resection for CD between January 2003 and December 2014. All data were collected from the general electronic data system of the Hospital da Senhora da Oliveira, Guimarães, Portugal.

Patients with incomplete surgical resection and positive margins on the surgical specimen; who were scheduled for a follow-up period of $<1$ year; who had previous history of strictureplasty, bowel or colonic resection, and perianal surgery; and who did not undergo colonoscopy within 1 year after surgery were excluded. The median time to the first ileocolonoscopy after surgery was determined.

Patients were classified into two groups according to the Rutgeerts' score (3): non-ER (Rutgeerts i0/i1) and ER (Rutgeerts $\geq i 2)$. The potential risk factors for ER $(\geq i 2)$ were analyzed and divided into four groups: factors related to the patient, disease, surgery, and pharmacological treatment.

Regarding the indication for surgery, patients were divided into two groups (6). Perforating indication was defined as acute free perforation, subacute perforation with an abscess, and chronic perforation fistula formation. Non-perforating indication was defined as intestinal obstruction, medical intractability, hemorrhage, and toxic dilation (6).

This study was conducted according to principles of the World Medical Association Declaration of Helsinki. Anonymous clinical data were obtained after each patient agreed to the procedure by providing written informed consent.

\section{Statistical Analysis}

Statistical analyses were performed using Statistical Package for Social Sciences version 20.0 (IBM Corp.; Armonk, NY, USA). A multivariate logistic regression analysis was performed that included only factors that were significant on univariable analysis to identify factors associated with ER. Thus, $p$ values of $<0.05$ were considered to be statistically significant.

\section{RESULTS}

Seventy patients of our center underwent ileocolic resection. Complete medical records were obtained from 58 patients; however, only 42 patients met our inclusion criteria. Of these, $50 \%$ were females and had a mean age of 29.2 years [interquartile range (IQR), 21-34.8 years] at CD diagnosis.

The first colonoscopy on follow-up was performed at an average of 9 months (IQR, 6-12 months) after surgery, and an overall ER was observed in $59.5 \%$ of patients ( 25 of 42 ); of those, $52 \%$ of patients ( 13 of 25 ) had severe ER ( $\geq i 3$ ) (Table 1).

Clinical observations and demographics of these patients and their medical therapy were comparable between the ER and
Table 1. Rutgeerts' score

\begin{tabular}{lc}
\hline Rutgeerts & N (\%) \\
\hline i0 & $14(33.3)$ \\
i1 & $3(7.1)$ \\
i2 & $12(28.6)$ \\
i3 & $8(19)$ \\
i4 & $5(11.9)$ \\
\hline
\end{tabular}

Table 2. Factors related to the patient and to medical therapy

\begin{tabular}{lccr}
\hline Variable & ER & Non-ER & $\mathbf{p}$ \\
\hline Gender & 11 & 10 & 0.346 \\
$\quad$ Female & 14 & 7 & \\
$\quad$ Male & 2 & 0 & 0.506 \\
Family history of IBD & $30.3 \pm 10.9$ & $35.3 \pm 10.2$ & 0.14 \\
Age at surgery (years) & &
\end{tabular}

(mean \pm SD)

\section{Smoking}

$\begin{array}{lcc}\text { Never smoked } & 16 & 9 \\ \text { Current smoker } & 8 & 5 \\ \text { Ex-smoker } & 1 & \end{array}$

\section{Preoperative medications}

$\begin{array}{lccc}\text { Corticosteroids } & 13 & 6 & 0.353 \\ \text { Mesalamine } & 12 & 6 & 0.414 \\ \text { Azathioprine } & 11 & 8 & 1 \\ \text { Anti-TNF drugs } & 4 & 2 & 1\end{array}$

\section{Postoperative medications}

$\begin{array}{lccc}\text { Mesalamine } & 12 & 10 & 0.491 \\ \text { Azathioprine } & 19 & 12 & 0.733 \\ \text { Anti-TNF drugs } & 6 & 5 & 0.733\end{array}$

Start time of mesalamine $\quad 22.3 \pm 31.7 \quad 11.4 \pm 18.1 \quad 0.350$ after surgery (days)

(mean \pm SD)

\begin{tabular}{lccc}
$\begin{array}{l}\text { Start time of AZT } \\
\text { after surgery (days) } \\
\text { (mean } \pm \text { SD) }\end{array}$ & $38.7 \pm 28.9$ & $76.3 \pm 68.9$ & 0.083 \\
$\begin{array}{l}\text { Start time of anti-TNF } \\
\text { drugs after surgery } \\
\text { (days) (mean } \pm \text { SD) }\end{array}$ & $49.8 \pm 36.7$ & $44.4 \pm 17.2$ & 0.769 \\
\hline
\end{tabular}

AZT: azathioprine; ER: endoscopic recurrence; IBD: inflammatory bowel disease; SD: standard deviation; TNF: tumor necrosis factor

non-ER groups (Table 2). None of these factors were associated with ER. The median age of the patients at the time of resection was 32.3 years (IQR, 23-41.3 years).

At the time of surgery, 25 patients (59.5\%) had never smoked, 13 (31\%) were current smokers, and 4 (9.5\%) were ex-smokers. 
Table 3. Disease related factors

\begin{tabular}{|c|c|c|c|}
\hline & ER & Non-ER & $\mathrm{p}$ \\
\hline \multicolumn{4}{|l|}{ Age at diagnosis } \\
\hline$A 2$ & 19 & 14 & 0.716 \\
\hline A3 & 6 & 3 & \\
\hline \multicolumn{4}{|l|}{ Disease location } \\
\hline L1 & 10 & 5 & 0.482 \\
\hline L3 & 15 & 12 & \\
\hline \multicolumn{4}{|l|}{ Disease behavior } \\
\hline B2 & 8 & 5 & 0.859 \\
\hline B3 & 12 & 17 & \\
\hline Perianal disease & 13 & 2 & 0.008 \\
\hline $\begin{array}{l}\text { Disease Duration } \\
\text { (months) (mean } \pm S D)\end{array}$ & $13.9 \pm 17.7$ & $59.2 \pm 70.4$ & 0.019 \\
\hline $\begin{array}{l}\text { ERS }(\mathrm{mm} / \text { hour }) \\
(\mathrm{mean} \pm \mathrm{SD})\end{array}$ & $18.8 \pm 14.7$ & $15.1 \pm 14.3$ & 0.423 \\
\hline $\begin{array}{l}\text { CRP }(\mathrm{mg} / \mathrm{L}) \\
(\mathrm{mean} \pm \mathrm{SD})\end{array}$ & $8.8 \pm 16.5$ & $7.2 \pm 13.1$ & 0.727 \\
\hline
\end{tabular}

Table 4. Surgery-related factors

\begin{tabular}{|c|c|c|c|}
\hline & ER & Non-ER & $p$ \\
\hline \multicolumn{4}{|l|}{ Timing of surgery } \\
\hline Elective & 14 & 10 & 0.856 \\
\hline Urgent & 11 & 7 & \\
\hline \multicolumn{4}{|l|}{ Indication } \\
\hline Perforating & 17 & 11 & 0.824 \\
\hline Non-perforating & 8 & 6 & \\
\hline \multicolumn{4}{|l|}{ Surgical procedure } \\
\hline Open & 23 & 16 & 1 \\
\hline Laparoscopic & 2 & 1 & \\
\hline \multicolumn{4}{|l|}{ Type of anastomosis } \\
\hline Side to side & 24 & 16 & 1 \\
\hline End to side & 1 & 1 & \\
\hline Postoperative complications & 3 & 3 & 0.672 \\
\hline Intra-abdominal abscess & 1 & 2 & 0.556 \\
\hline Anastomotic dehiscence & 2 & 1 & 1 \\
\hline $\begin{array}{l}\text { Extension of the specimen } \\
(\mathrm{cm})(\text { mean } \pm S D)\end{array}$ & $37.7 \pm 16.1$ & $36.2 \pm 25.2$ & 0.813 \\
\hline $\begin{array}{l}\text { Granulomas in surgical } \\
\text { specimen wall }\end{array}$ & 12 & 7 & 0.663 \\
\hline $\begin{array}{l}\text { Granulomas in mesenteric } \\
\text { lymph nodes }\end{array}$ & 2 & 4 & 0.202 \\
\hline
\end{tabular}

ER: endoscopic recurrence; SD: standard deviation
Only 2 patients (4.8\%) had a family history of inflammatory bowel disease.

The choice to initiate prophylactic therapy after surgery with azathioprine, anti-TNF drugs, or both in combination were based on the penetrating phenotype and other aggressive disease factors, such as perianal disease and age $<40$ years at diagnosis in $83.3 \%$ of patients (35 of 42 ).

After surgery, 31 patients took azathioprine; of these, 19 had ER $(p=0.733)$. Eleven patients took anti-tumor necrosis factor (anti-TNF) drugs after surgery; of these, 6 had ER $(p=0.733)$. Disease-related factors were compared between the two groups, as shown in Table 3. The median duration between CD diagnosis and surgery was 32 months (range, 0-254 months).

According to the Montreal classification, the majority of our patients were A2 (78.6\%). Regarding the disease location, 35.7\% exhibited disease in the ileum (L1),64.3\% in the ileocolic, and none with only colon involvement. Patients mainly presented with penetrating behavior (L3) (69\%), and 31\% had stricturing disease (L2). None of the patients concomitantly presented with upper gastrointestinal tract involvement.

Of the 15 patients with perianal disease, 13 had ER on follow-up $(p=0.008)$. There was a higher incidence of $E R$ in patients with a shorter duration of disease (13.9 vs. 59.2 months, with ER and non-ER, respectively, $p=0.019)$. Table 4 shows surgery-related factors that were compared between the two groups.

Patients underwent ileocolic resection for strictures (33.3\%), abscess and fistula (52.4\%), and free perforation (14.3\%). Among the 28 patients with perforating indications, 17 had ER; eight of the 14 patients with non-perforating indications had $E R$, without significant statistical difference between the two groups $(p=0.824)$.

An urgent operation was performed in 18 patients (42.9\%).

The mean length of the intestine resected was $37.1 \pm 20 \mathrm{~cm}$, none with a large intestinal resection. We found no association with regard to the intestine length resected and ER ( $p=0.813$ ).

The presence of wall granulomas was noted in 19 patients (45.2\%), 12 in ER patients, and 7 in patients without ER $(p=0.663)$. The granulomas of mesenteric lymph nodes were identified in 6 (14.3\%) patients: 2 with ER and 4 without ER $(p=0.202)$.

In the multivariate analysis, the perianal disease and shorter duration of CD remained the only ER predictors $(p=0.024$; OR, 8.36; $95 \% \mathrm{Cl}, 1.329-52.642$ and $p=0.039 ;$ OR. 0.965; $95 \% \mathrm{Cl}$. 0.933-0.998, respectively). 


\section{DISCUSSION}

Crohn disease surgery is not curative because the disease often recurs in the remaining bowel (3). According to the European Crohn's and Colitis Organisation consensus, the following factors have been shown to predict early postoperative recurrence in the majority of studies: smoking, prior intestinal surgery, penetrating disease behavior, perianal involvement, and extended small bowel resection $(>100 \mathrm{~cm})(7)$.

Although they are, by consensus, risk factors for postoperative recurrence, there are a disparity of results between several studies that may be explained by the ambiguous definition of disease recurrence and the type and number of predictors factors included. In fact, according to the literature, the recurrence rate varies as per the criteria used for diagnosis: clinical, endoscopic, radiological, or surgical.

The term recurrence refers to the appearance of lesions after surgery, which is evaluated using imaging methods (as ultrasound, computed tomography, or magnetic resonance imaging) or using endoscopy (7). Currently, ileocolonoscopy is the first-line method for diagnosing postoperative ER and is recommended to be performed during the first year after surgery (7).

Our analysis evaluated ER after and between 6-12 months of surgery according to the Rutgeerts' score and compared the risk factors between groups with ER and without ER. After ileocolic resection, we observed an ER of $59.5 \%$ after a mean of 9 months.

There was no statistical difference regarding sex and age at surgery between the groups with ER and without ER. Actually, sex has not been proven to be a risk factor for $\operatorname{ER}(7,8)$. Additionally, there is conflicting evidence regarding the effect of age on the risk for $E R$; therefore, it is not a definite risk factor for $\operatorname{ER}(7,9,10)$.

Although we did not find a statistically significant difference in ER between the groups of smokers and nonsmokers probably because we had few smoker patients, most studies showed that it is a modifiable patient-related independent predictor (10-13).

As per the Montreal classification, none of the parameters showed a statistical difference relative to ER. Although in this study, the behavior of the disease according to the Montreal classification has not been shown to be a predictor of ER, the majority of our patients had a penetrating phenotype, and this has been consistently known to be a risk factor for an aggressive disease course and a predictor of ER in the literature (14-16).

In this study, the presence of perianal disease increased the risk for ER. It is well known that patients with a perianal disease are a subgroup of patients with a more severe disease, which has been associated to an increased risk for $\operatorname{ER}(2,17)$.
A shorter duration of CD in the ER group was found, with a statistical difference from the non-ER group, and has been established as a risk factor in our study. However, there is conflicting data regarding the association of the disease duration with the risk for ER (9). Several studies have shown the association between ER and the duration of the disease. Pogglioli et al. (18) found a higher incidence of ER in patients with disease duration of $<6$ years compared with patients with a duration of CD of $>6$ years. In contrast, Lautenbach et al. (19) found an association between the longer duration of disease and surgery.

The majority of patients had a perforating indication for surgery. We found no significant difference in ER between perforating and non-perforating indications. The role of surgical indication in CD recurrence remains controversial, with some studies suggesting that perforating $C D$ results in a higher recurrence rate compared with non-perforating CD, whereas other studies have not shown a difference in recurrence (6,20-22).

In our series, there was no association between the extension of the surgical resection specimen and ER maybe because we did not have any case of extensive resection. Several studies have demonstrated that recurrence is higher after a long length resection of the diseased bowel (2). However, other studies have not shown this association (23).

There are contradictory reports about granulomas in the resection specimen on recurrence (16,24-26). In a recent report, the presence of granulomas in the mesenteric lymph nodes was found to be an independent risk factor for ER (27).

Several medications, such as mesalamine or antibiotics, have been advocated for the prevention of postoperative disease recurrence $(28,29)$. However, the marginal role of mesalamine for preventing ER is currently known and with regard to metronidazole, loss of efficacy beyond 12 months and side effects precludes its use in the prevention of $\operatorname{ER}(7,29,30)$.

Thiopurines have been shown to reduce endoscopic and clinical recurrence postoperatively (31). Recent reports suggest that anti-TNF drugs, infliximab, and adalimumab can delay and reduce postoperative recurrence $(32,33)$.

Statistically, postoperative medication (thiopurines or anti-TFN drugs) did not affect the rate of ER. This might be due to the fact that only 11 patients (26.2\%) had not taken thiopurines and only 11 patients (26.2\%) have been treated with anti-TNF drugs post-surgery. However, we can raise the hypothesis that the high number of our patients who maintained thiopurines post-surgery can decrease the ER rate because our rate of ER $(59.5 \%)$ is lower than the Rutgeerts reports $(3,4)$.

The optimal monitoring and prophylaxis strategy for postoperative recurrence has not been established. Some authors recommend prophylaxis with thiopurines, soon after surgery, 
in high-risk patients (34). De Cruz et al. (35) recently reported that treatment, according to recurrence risk, and adjusting it on the basis of ileocolonoscopy findings at 6 months after surgery is better than conventional drug therapy alone for preventing postoperative $C D$ recurrence.

There are several limitations to our study because it is a retrospective study design that reviews medical records and the number of included patients in each group may preclude a significant $p$ value.

Nevertheless, our study revealed that almost two-thirds of CD patients had ER. Most of these had a severe ER ( $\geq i 3)$, with important implications for prognosis, with perianal involvement, and a shorter duration of disease, being significant risk factors. Therefore, identification of patients at high risk for ER allows a targeted approach of these patients, benefiting from increased monitoring and therapeutic prophylaxis and hoping for a better prognosis for these patients.

Further studies designed to analyze the impact of immediate prophylaxis after surgery in identified high-risk patients is warranted to find the best practice for these patients.

Ethics Committee Approval: Authors declared that the research was conducted according to the principles of the World Medical Association Declaration of Helsinki "Ethical Principles for Medical Research Involving Human Subjects", (amended in October 2013).

Informed Consent: Written informed consent was obtained from patients who participated in this study.

Peer-review: Externally peer-reviewed.

Author contributions: Concept - S.M., T.C.G., P.B.C.; Design - S.M., T.C.G., P.B.C.; Supervision - S.M., M.J.M., J.C.; Resource - S.M., T.C.G., P.B.C., M.J.M., J.C.; Materials - M.J.M., J.C.; Data Collection and/or Processing - S.M., T.C.G., P.B.C.; Analysis and/or Interpretation - S.M., T.C.G., P.B.C.; Literature Search - S.M.; Writing - S.M., T.C.G., M.J.M.; Critical Reviews - M.J.M., J.C.

Conflict of Interest: No conflict of interest was declared by the authors.

Financial Disclosure: The authors declared that this study has received no financial support.

\section{REFERENCES}

1. Peyrin-Biroulet L, Loftus EV, Jr, Colombel JF, Sandborn WJ. The natural history of adult Crohn's disease in population-based cohorts. Am J Gastroenterol 2010; 105: 289-97. [CrossRef]

2. Bernell $O$, Lapidus A, Hellers G. Risk factors for surgery and recurrence in 907 patients with primary ileocaecal Crohn's disease. Br J Surg 2000; 87: 1697-701. [CrossRef]

3. Rutgeerts P, Geboes K, Vantrappen G, Beyls J, Kerremans R, Hiele M. Predictability of the postoperative course of Crohn's disease. Gastroenterology 1990; 99: 956-63. [CrossRef]

4. Rutgeerts P, Geboes K, Vantrappen G, Kerremans R, Coenegrachts $J$, Coremans G. Natural history of recurrent Crohn's disease at the ileocolonic anastomosis after curative surgery. Gut 1984; 25: 66572. [CrossRef]
5. Magalhães J, Castro FD, Carvalho PB, Moreira MJ, Cotter J. Quality of life in patients with inflammatory bowel disease: importance of clinical, demographic and psychosocial factors. Arq Gastroenterol 2014; 51: 192-7. [CrossRef]

6. Greenstein AJ, Lachman P, Sachar DB, et al. Perforating and nonperforating indications for repeated operations in Crohn's disease: evidence for two clinical forms. Gut 1988; 29: 588-92. [CrossRef]

7. Van Assche G, Dignass A, Reinisch W, et al. The second European evidence-based Consensus on the diagnosis and management of Crohn's disease: Special situations. J Crohns Colitis 2010; 4: 63101. [CrossRef]

8. De Cruz P, Kamm MA, Prideaux L, Allen PB, Desmond PV. Postoperative recurrent luminal Crohn's disease: a systematic review. Inflamm Bowel Dis 2012; 18: 758-77. [CrossRef]

9. Caprilli R, Corrao G, Taddei G, Tonelli F, Torchio P, Viscido A. Prognostic factors for postoperative recurrence of Crohn's disease. Gruppo Italiano per lo Studio del Colon e del Retto (GISC). Dis Colon Rectum 1996; 39: 335-41. [CrossRef]

10. Ryan WR, Allan RN, Yamamoto T, Keighley MR. Crohn's disease patients who quit smoking have a reduced risk of reoperation for recurrence. Am J Surg 2004; 187: 219-25. [CrossRef]

11. Cottone M, Rosselli M, Orlando A, et al. Smoking habits and recurrence in Crohn's disease. Gastroenterology 1994; 106: 643-8. [CrossRef]

12. Sutherland LR, Ramcharan S, Bryant H, Fick G. Effect of cigarette smoking on recurrence of Crohn's disease. Gastroenterology 1990; 98: 1123-8. [CrossRef]

13. Reese GE, Nanidis T, Borysiewicz C, Yamamoto T, Orchard T, Tekkis PP. The effect of smoking after surgery for Crohn's disease: a meta-analysis of observational studies. Int J Colorectal Dis 2008; 23: 1213-21. [CrossRef]

14. Beaugerie L, Seksik P, Nion-Larmurier I, Gendre JP, Cosnes J. Predictors of Crohn's disease. Gastroenterology 2006; 130: 650-6. [CrossRef]

15. Sachar DB, Lemmer E, Ibrahim C, et al. Recurrence patterns after first resection for stricturing or penetrating Crohn's disease. Inflamm Bowel Dis 2009; 15: 1071-5. [CrossRef]

16. Hofer B, Böttger T, Hernandez-Richter T, Seifert JK, Junginger T. The impact of clinical types of disease manifestation on the risk of early postoperative recurrence in Crohn's disease. Hepatogastroenterology 2001; 48: 152-5.

17. Whelan G, Farmer RG, Fazio VW, Goormastic M. Recurrence after surgery in Crohn's disease. Relationship to location of disease (clinical pattern) and surgical indication. Gastroenterology 1985; 88: 1826-33. [CrossRef]

18. Poggioli G, Laureti $S$, Selleri $S$, et al. Factors affecting recurrence in Crohn's disease. Results of a prospective audit. Int J Colorectal Dis 1996; 11: 294-8. [CrossRef]

19. Lautenbach E, Berlin JA, Lichtenstein GR. Risk factors for early postoperative recurrence of Crohn's disease. Gastroenterology 1998; 115: 259-67. [CrossRef]

20. Simillis C, Yamamoto T, Reese GE, et al. A meta-analysis comparing incidence of recurrence and indication for reoperation after surgery for perforating versus nonperforating Crohn's disease. Am J Gastroenterol 2008; 103: 196-205. [CrossRef]

21. McDonald PJ, Fazio VW, Farmer RG, et al. Perforating and nonperforating Crohn's disease. An unpredictable guide to recurrence after surgery. Dis Colon Rectum 1989; 32: 117-20. [CrossRef]

22. Yamamoto T, Allan RN, Keighley MR. Perforating ileocecal Crohn's disease does not carry a high risk of recurrence but usually re-pres- 
ents as perforating disease. Dis Colon Rectum 1999; 42: 519-24. [CrossRef]

23. Ellis L, Calhoun P, Kaiser DL, Rudolf LE, Hanks JB. Postoperative recurrence in Crohn's disease. The effect of the initial length of bowel resection and operative procedure. Ann Surg 1984; 199: 340-7. [CrossRef]

24. Bressenot A, Peyrin-Biroulet L. Histologic features predicting postoperative Crohn's disease recurrence. Inflamm Bowel Dis 2015; 21: 468-75. [CrossRef]

25. Anseline PF, Wlodarczyk J, Murugasu R. Presence of granulomas is associated with recurrence after surgery for Crohn's disease: experience of a surgical unit. Br J Surg 1997; 84: 78-82. [CrossRef]

26. Glass RE, Baker WN. Role of the granuloma in recurrent Crohn's disease. Gut 1976; 17: 75-7. [CrossRef]

27. Li Y, Stocchi L, Liu X, et al. Presence of granulomas in mesenteric lymph nodes is associated with postoperative recurrence in Crohn's disease. Inflamm Bowel Dis 2015; 21: 2613-8. [CrossRef]

28. McLeod RS, Wolff BG, Steinhart AH, et al. Prophylactic mesalamine treatment decreases postoperative recurrence of Crohn's disease. Gastroenterology 1995; 109: 404-13. [CrossRef]

29. Rutgeerts P, Hiele M, Geboes K, et al. Controlled trial of metronidazole treatment for prevention of Crohn's recurrence after ileal resection. Gastroenterology 1995; 108: 1617-21. [CrossRef]
30. Orlando A, Mocciaro F, Renna S, et al. Early post-operative endoscopic recurrence in Crohn's disease patients: data from an Italian Group for the study of inflammatory bowel disease (IG-IBD) study on a large prospective multicenter cohort. J Corhns Colitis 2014; 8: 1217-21. [CrossRef]

31. Peyrin-Biroulet $L$, Deltenre $P$, Ardizzone $S$, et al. Azathioprine and 6-mercaptopurine for the prevention of postoperative recurrence in Crohn's disease: a meta-analysis. Am J Gastroenterol 2009; 104: 2089-96. [CrossRef]

32. Savarino E, Bodini G, Dulbecco P, et al. Adalimumab is more effective than azathioprine and mesalamine at preventing postoperative recurrence of Crohn's disease: a randomized controlled trial. Am J Gastroenterol 2013; 108: 1731-42. [CrossRef]

33. Regueiro M, Schraut W, Baidoo L, et al. Infliximab prevents Crohn's disease recurrence after ileal resection. Gastroenterology 2009; 136: 441-50. [CrossRef]

34. Yamamoto T, Watanabe T. Strategies for the prevention of postoperative recurrence of Crohn's disease. Colorectal Dis 2013; 15: 1471-80. [CrossRef]

35. De Cruz P, Kamm MA, Hamilton AL, et al. Crohn's disease management after intestinal resection: a randomised trial. Lancet 2015; 385: 1406-17.[CrossRef] 